\title{
Oncologist Bum
}

\section{In the End What Matters Most? A Review of Clinical Endpoints in Advanced Breast Cancer}

\author{
Sunil Verma, ${ }^{\text {a Deanna MCLeod, }}{ }^{\mathrm{b}}$ Gerald Batist, ${ }^{\text {c }}$ André Robidoux, ${ }^{\text {d }}$ Ilídio R. S. Martins, \\ JOHN R. MACKEY \\ ${ }^{\mathrm{a}}$ Sunnybrook Odette Cancer Centre, University of Toronto, Toronto, Ontario, Canada; ${ }^{\mathrm{b}}$ Kaleidoscope \\ Strategic, Toronto, Ontario, Canada; ${ }^{\mathrm{C}} \mathrm{Segal}$ Cancer Centre/Jewish General Hospital/Lady Davis Institute, \\ McGill University, Montréal, Québec, Canada; ${ }^{\mathrm{d} C e n t r e ~ H o s p i t a l i e r ~ d e ~ l ' U n i v e r s i t e ́ ~ d e ~ M o n t r e ́ a l, ~ M o n t r e ́ a l, ~}$ \\ Québec, Canada; ${ }^{\mathrm{e} C r o s s}$ Cancer Institute, University of Alberta, Edmonton, Alberta, Canada
}

Key Words. Metastatic • Breast cancer - Surrogate endpoint $・$ Clinical trial design $・$ Regulatory approval FDA

Disclosures: Sunil Verma: Consultant/advisory role: sanofi-aventis, Roche, GlaxoSmithKline; Honoraria: Roche; Research funding/contracted research: sanofi-aventis, Roche; Deanna McLeod: Research funding/contracted research: Hoffmann-La Roche Inc; Employment/leadership position: Kaleidoscope Strategic; Gerald Batist: None; André Robidoux: None; Ilídio R. S. Martins: Employment/leadership position: Kaleidoscope Strategic; John R. Mackey: None.

The content of this article has been reviewed by independent peer reviewers to ensure that it is balanced, objective, and free from commercial bias. No financial relationships relevant to the content of this article have been disclosed by the independent peer reviewers.

\begin{abstract}
Many agents are being studied for the treatment of metastatic breast cancer (MBC), yet few studies have demonstrated longer overall survival (OS), the primary measure of clinical benefit in MBC. This paper examines the key endpoints in clinical trials and U.S. Food and Drug Administration (FDA) approvals of drugs for MBC.

PubMed was searched (1980 to October 2009) for reports of phase III trials investigating chemotherapy and/or targeted therapy agents in MBC. FDA approval histories (1996-2009) for cytotoxic and biological agents indicated for $\mathrm{MBC}$ were reviewed.

Of the 73 phase III MBC trials reviewed, a strikingly small proportion of trials demonstrated a gain in OS duration $(12 \%, n=9)$. OS gains were less frequently noted in first-line trials $(8 \%)$ than in trials of second-line plus
\end{abstract}

other lines of therapy ( $22 \%$ ). Few trials were designed with the capacity to detect OS effects. Among 37 phase III trials conducted in the last 15 years, only three systemic therapies were approved for first-line use and nine were approved for use as second-line or other lines of therapy. Of these, only four were supported by results showing longer survival times.

There is substantial discordance among the design and conduct of clinical trials, FDA drug approval, and the current view of $\mathrm{OS}$ as the ultimate measure of clinical benefit. There is an urgent need to reassess standards for clinical benefit in MBC and to establish guidelines for study design and conduct and drug approval. In the end, what matters most is ensuring rapid access to safe and effective oncology treatments. The Oncologist 2011;16:25-35 


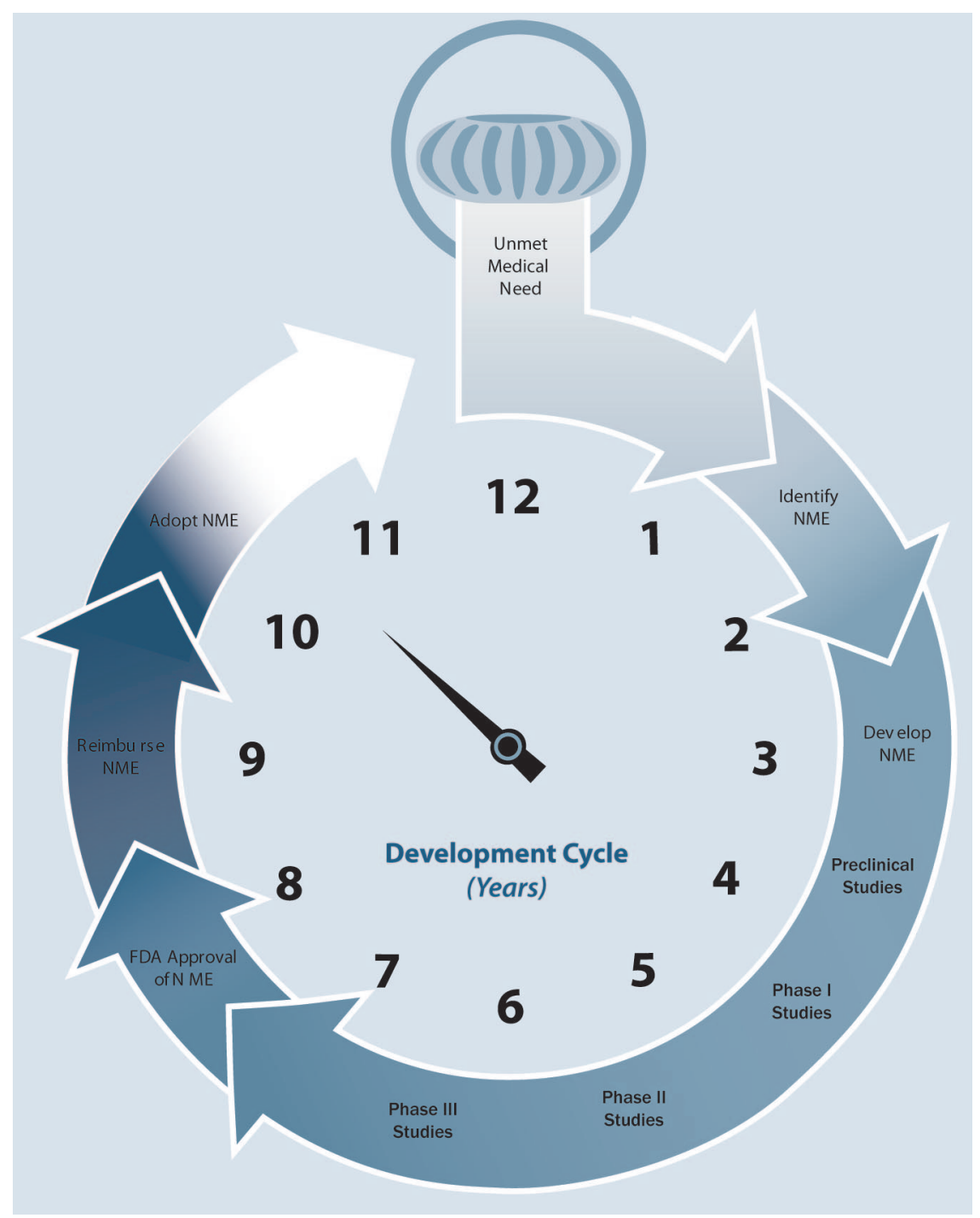

Figure 1. The cycle of NME development for metastatic breast cancer.

Abbreviations: FDA, U.S. Food and Drug Administration; NME, new molecular entity.

\section{INTRODUCTION}

Despite the availability of an unprecedented number of clinically active antitumor agents for the treatment of metastatic breast cancer (MBC), the disease remains incurable. Current clinical goals are to prolong life while maintaining optimal quality of life, underscoring the importance of earlier access to safe and effective new treatments.

\section{Clinical Trial Design and Endpoints}

The process by which clinicians gain access to new molecular entities (NMEs) is complex, involves multiple stages and stakeholders, and is somewhat cyclical (Fig. 1). Clinical trial results, particularly those from phase III trials, form the basis for regulatory review, reimbursement review, and ultimately adoption or rejection by the medical community. Therefore, clinical trial design, and specifically the selec- tion of the primary endpoint, is pivotal because it defines how the clinical benefit will be measured, determines the size of the trial, and determines the length of follow-up required.

\section{Survival as an Endpoint}

Overall survival (OS) is defined as the time from randomization to death from any cause $[1,2]$ and has historically been regarded as the gold standard measure of clinical benefit [3]. OS is favored due to its objectivity, clear indication of benefit, and ease and reliability of measurement. However, determination of OS also requires a larger sample size, requires a prolonged follow-up period, and may be influenced by therapies used after patient participation in a given trial has ended, including crossover to the experimental arm. This has been of increasing concern because, over the last decade, significant advances in the systemic treatment 
Table 1. Meta-analyses of randomized controlled trials evaluating PFS or TTP as surrogates for OS

\begin{tabular}{|c|c|c|c|c|c|c|c|c|c|}
\hline Study & $\begin{array}{l}n \text { of } \\
\text { patients }\end{array}$ & $\begin{array}{l}n \text { of } \\
\text { RCTs }\end{array}$ & $\begin{array}{l}\text { Nature of } \\
\text { intervention }\end{array}$ & $\begin{array}{l}\text { Surrogate } \\
\text { endpoint }\end{array}$ & $\begin{array}{l}\text { True } \\
\text { endpoint }\end{array}$ & $\begin{array}{l}\text { Individual } \\
\text { patient data } \\
\text { (yes/no) }\end{array}$ & Measure of treatment effect & $\begin{array}{l}\text { Results (effects and } \\
\text { criteria for correlation) }\end{array}$ & $\begin{array}{l}\text { Study } \\
\text { outcome }\end{array}$ \\
\hline $\begin{array}{l}\text { Hackshaw et } \\
\text { al. (2005) [4] }\end{array}$ & 9,163 & 42 & $\begin{array}{l}\text { FEC or FAC versus } \\
\text { other chemotherapy }\end{array}$ & TTP & OS & No & HR (OS), OR (TTP) & $\begin{array}{l}\text { TTP-logOR versus OS- } \\
\operatorname{logHR:} \mathrm{m}=0.51, R^{2}= \\
56 \%, \mathrm{SE}=0.0928 ; p= \\
.0001\end{array}$ & Positive (TTP) \\
\hline $\begin{array}{l}\text { Burzykowski } \\
\text { et al. (2008) } \\
\text { [7] }\end{array}$ & 3,953 & 11 & $\begin{array}{l}\text { Anthracycline- } \\
\text { containing } \\
\text { regimens versus } \\
\text { taxane or taxane }+ \\
\text { anthracycline }\end{array}$ & PFS, TTP & OS & Yes & $\operatorname{logHR}(\mathrm{PFS}, \mathrm{TTP}, \mathrm{OS})$ & $\begin{array}{l}\text { PFS- } \log H R \text { versus OS- } \\
\text { logHR: } \mathrm{CC}=0.48,95 \% \\
\text { CI, } 0.34-1.30 ; \text { TTP- } \\
\text { logHR versus OS-logHR: } \\
\mathrm{CC}=0.49,95 \% \mathrm{CI} \text {, } \\
0.32-1.30\end{array}$ & $\begin{array}{l}\text { Negative } \\
\text { (PFS, TTP) }\end{array}$ \\
\hline $\begin{array}{l}\text { Miksad et al. } \\
\text { (2008) [5] }\end{array}$ & 10,216 & 31 & $\begin{array}{l}\mathrm{FEC} \text { or } \mathrm{FAC} \text { and } \\
\text { taxane-containing } \\
\text { regimens }\end{array}$ & PFS & OS & No & HR (PFS, OS) & $\begin{array}{l}\kappa(\operatorname{ant}): 0.71,95 \% \mathrm{CI}, \\
0.36-1.00, p=.0029 ; \kappa \\
(\operatorname{tax}): 0.75,95 \% \mathrm{CI}, 0.42- \\
1.00, p=.0028 ; \text { PFS-HR } \\
\text { versus OS-HR (ant): } p= \\
.0019, R^{2}=0.49 ; \text { PFS- } \\
\text { HR versus OS-HR (tax): } \\
p=.012, R^{2}=0.35\end{array}$ & Positive (PFS) \\
\hline $\begin{array}{l}\text { Sherrill et al. } \\
\text { (2008) [6] }\end{array}$ & 17,081 & 67 & $\begin{array}{l}\text { Chemotherapy, } \\
\text { hormonal therapy, } \\
\text { and targeted } \\
\text { therapy }\end{array}$ & $\begin{array}{l}\text { PFS or } \\
\text { TTP }\end{array}$ & OS & No & $\begin{array}{l}\mathrm{HR}(\mathrm{PFS} / \mathrm{TTP}, \mathrm{OS}) ; \text { Effect }_{\mathrm{TTP}}= \\
\mathrm{HR}_{\mathrm{TTP}}-1 ; \text { Effect }_{\mathrm{OS}}= \\
\mathrm{HR}_{\mathrm{OS}}-1\end{array}$ & $\begin{array}{l}\text { Effect }_{\mathrm{OS}}=0.32(95 \% \mathrm{CI} \\
0.20-0.43) \times \text { Effect }_{\mathrm{TTP}} \\
R^{2}=0.30\end{array}$ & $\begin{array}{l}\text { Positive (PFS } \\
\text { or TTP) }\end{array}$ \\
\hline
\end{tabular}

of MBC have dramatically altered the number and variety of available treatments that are used sequentially. The usefulness of OS as a trial endpoint in an era of effective subsequent-line agents must now be reconsidered.

\section{Progression-Free Survival and Time to Progression as Endpoints}

Time-to-event endpoints, such as progression-free survival (PFS) and the related endpoint time to progression (TTP), focus on progression of disease and were previously considered of secondary significance compared with OS. Initial interest in PFS and TTP as measures of clinical benefit in $\mathrm{MBC}$ began with their potential as surrogate endpoints for survival. Although some degree of association has been detected between PFS/TTP and OS [4-6] (Table 1), results remain inconsistent [4-7], and the nature of the relationship is uncertain. Nevertheless, these endpoints have been increasingly used as primary endpoints and are now the most frequently used endpoints in ongoing randomized MBC trials. Although their definitions are not standardized [5, 8], the U.S. Food and Drug Administration (FDA) defines PFS as the time elapsed between randomization and tumor progression or death from any cause and defines TTP as the time elapsed between randomization and disease progression $[1,2]$. The merits of using PFS and TTP as measures of clinical benefit are that they are reached faster than OS, are not influenced by subsequent treatments [1,9], and many consider these endpoints direct measures of clinical benefit [10-12]. One reservation has been that measurement of PFS/TTP is more involved, and therefore more susceptible to error and bias, although the direction of bias is not always evident $[1,9,13]$.

\section{Clinical Trial Endpoints and Regulatory Drug Approval}

The basis for FDA approvals of New Drug Applications or Biologics Licensing Applications is the sponsor's ability to demonstrate clinical benefit in adequate and well-controlled studies $[14,15]$. According to the FDA, clinical benefit can be established through improvements in OS, patient-reported outcomes such as symptom improvement, or an established surrogate endpoint $[1,16]$.

Two types of approval exist for drugs or biological products: regular approval and accelerated approval (AA). Regular approval requires evidence of clinical benefit or improvement in an established surrogate endpoint for clinical benefit, whereas AA requirements are less stringent [17]. The FDA established AA regulations in 1992. These regulations were designed to improve access to therapeutics for life-threatening diseases by allowing sponsors to begin marketing relevant drugs on the basis of trials that identify improvements in surrogate outcomes that are reasonably likely to predict clinical benefit, such as the response rate (RR) or PFS interval [18]. The use of AA was expanded to include NMEs for oncology through an initiative of the office of the President of the U.S. in 1996 [19] and the Food and Drug Administration Modernization Act of 1997 [20] (Fig. 2). Under the revised AA regulation, registration trials can be phase II or phase III; however, the sponsors are required to conduct confirmatory studies to verify clinical efficacy [17, 21]. In 1999, the Oncol- 


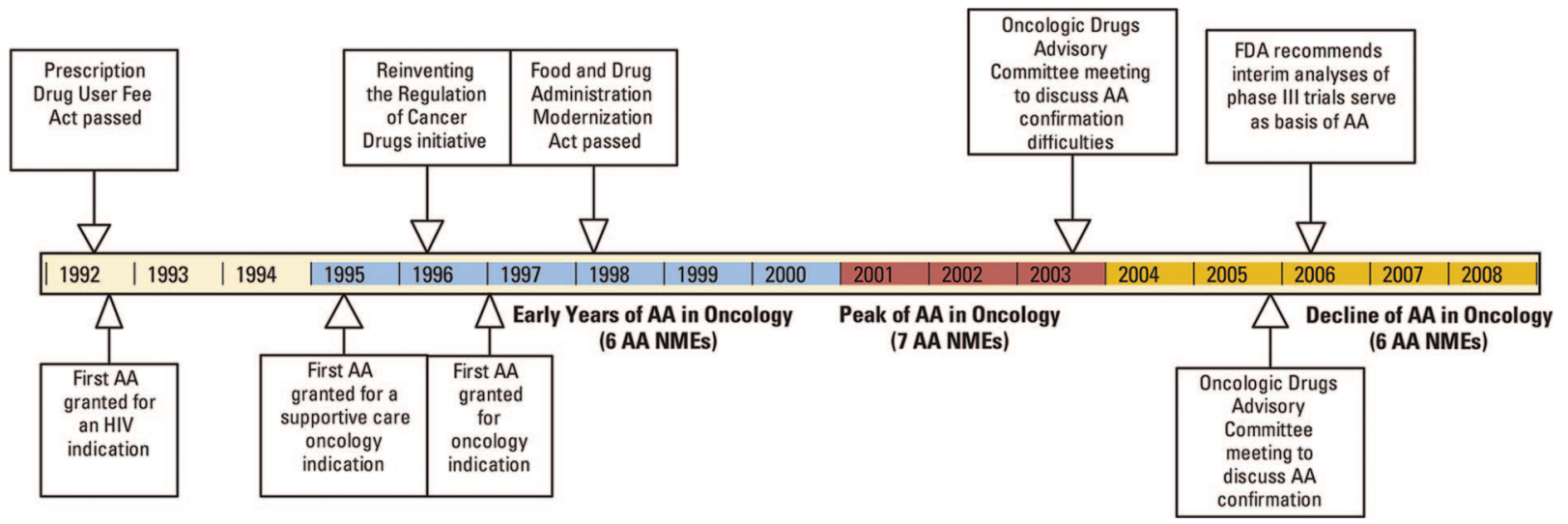

Figure 2. Changes in FDA regulatory approval from 1990 through 2008 [18].

Abbreviations: AA, accelerated approval; FDA, U.S. Food and Drug Administration; NME, new molecular entity.

From Richey EA, Lyons EA, Nebeker JR et al. Accelerated approval of cancer drugs: Improved access to therapeutic breakthroughs or early release of unsafe and ineffective drugs? J Clin Oncol 2009;27:4398 -4405. Reprinted by permission. (C2008 American Society of Clinical Oncology. All rights reserved.

ogy Drug Advisory Committee (ODAC) voted to maintain OS as the gold standard for regular approval of NME applications in MBC [22]. In 2003 and 2005, in response to recommendations made by the ODAC regarding AA applications, the FDA advised sponsors that single-arm, phase II studies would only be interpretable in the setting of refractory disease, whereas interim analyses of phase III trials could support AAs in a broad range of settings; additional follow-up of these trials could provide evidence of clinical benefit [15, 23].

In view of the key role played by endpoints in the drug development cycle and regulatory process, we sought to assess the effects of primary endpoint selection on clinical outcomes and regulatory approval.

\section{Clinical Trial Review}

\section{Clinical Trial Methods}

PubMed was searched for English language reports of phase III trials investigating chemotherapy and/or targeted therapy agents for MBC published between 1980 and October 2009. In total, 485 randomized clinical trials were identified using the terms "breast," "cancer," "advanced," and "therapy," and of these, 73 were confirmed as phase III trials reporting efficacy outcomes (Fig. 3). Randomized phase II trials and studies reporting pooled analyses were excluded. Because the intention of our analysis was to compare trends in FDA policy and practice with trends in study design, and it was believed that only phase III trials would be influential at the regulatory level, we opted to include only those trials with a phase III study-level designation. Studies without an explicit statement relative to trial phase were excluded from the analysis.

Data relating to the primary endpoint, line of treat-

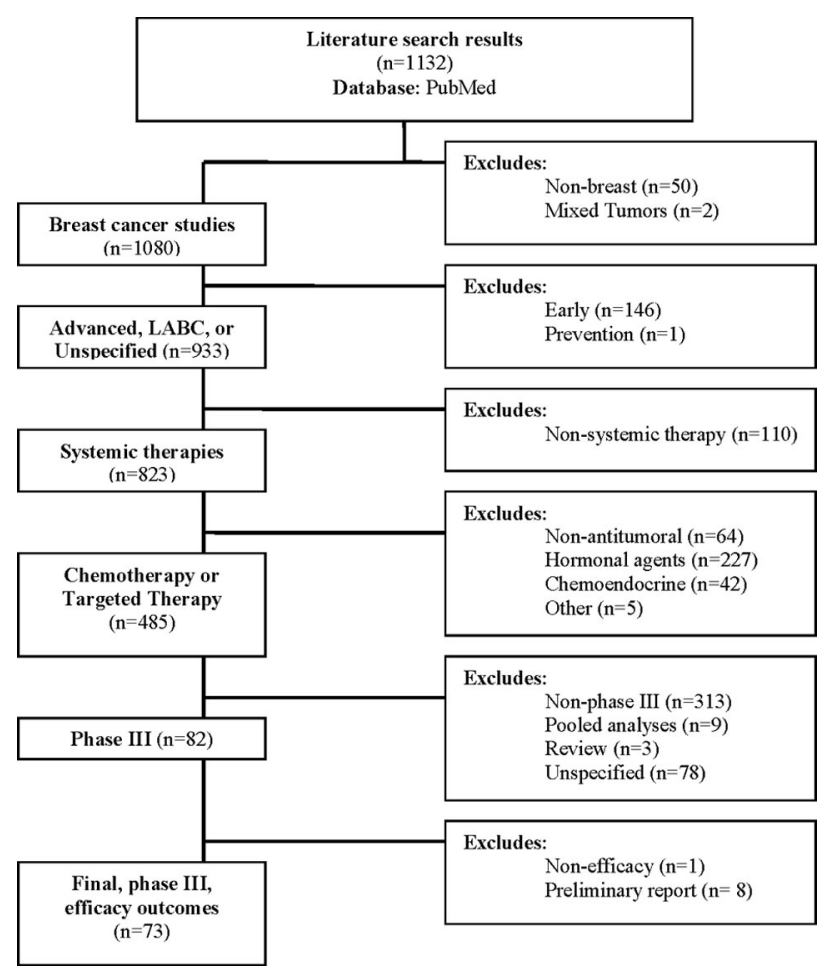

Figure 3. CONSORT diagram summarizing literature search eligibility criteria.

Abbreviation: LABC, locally advanced breast cancer.

ment, number of patients, and study start date were extracted from full source articles. In the absence of a clear statement regarding primary endpoint designation, endpoints used for sample size calculations were considered the primary endpoints. When multiple primary efficacy endpoints were identified, the primary endpoint was designated as not reported (NR). The studies were parsed 
into four primary endpoint categories: OS, PFS/TTP, RR (overall response rate [ORR] and/or complete response), and other endpoints. First-line MBC trials were defined as those trials with patient populations that had not received any prior chemotherapy or biologic therapy for metastatic disease. All other trials, including those with mixed populations of first-line patients and patients receiving prior therapy for $\mathrm{MBC}$ were categorized as second-line plus (second-line + ) trials.

In order to control for publication bias [24], study start dates were used for the historical analysis. Start dates were determined based on explicit statements in the original reports or through reference to secondary sources such as the ClinicalTrials.gov database. Start dates were not available in three studies and these were excluded from all point-intime analyses. Data were categorized into two time periods based on the median start year of our population of trials (1995). Two of the studies for which the start date could not be determined were published before $1995[25,26]$ and were included in the pre-1995 group. Significant improvement in an endpoint was defined as $p<.05$. In the analysis of trials with a $2 \times 2$ factorial design $(n=2)$, only the main comparisons were considered. For trials with more than two arms and without a factorial design, group $p$-values were used. When the number of "randomized" patients was not reported, we used the enrolled or registered population in the calculation of the number of randomized patients per arm. In the assessment of study results, we used the values reported for the intent-to-treat population preferentially.

\section{Clinical Trial Findings}

In total, 73 trials, corresponding to 152 trial arms, met the eligibility criteria for this review and were included in the analysis. These trials were conducted over three decades, with the first trial initiated in July 1978 and the last trial initiated in March 2004. A plot of phase III trials by start date (Fig. 4A) revealed a substantial increase in the number of trials initiated between 1994 and 1996, with the greatest number of trials initiated in 1996. A chronological analysis of the average number of patients randomized by arm showed that trial size increased substantially over the last three decades (Fig. 4B).

Of the 72 trials that could be unambiguously assigned to before or after 1995, 47 trials in total, or approximately two thirds (65\%) of the phase III trials, were first-line trials (Fig. $5 \mathrm{~A}$ ), whereas 23 trials in total, or approximately one third $(32 \%)$, were second-line + trials, of which the majority $(n=21)$ were a mix of first- and second-line patient populations. The line of treatment could not be determined in the remaining studies $(n=2,3 \%)$.

OS was reported as the primary endpoint in only $7 \%(n=$ 5) (Fig. 5B) of trials, whereas the PFS/TTP and RR primary
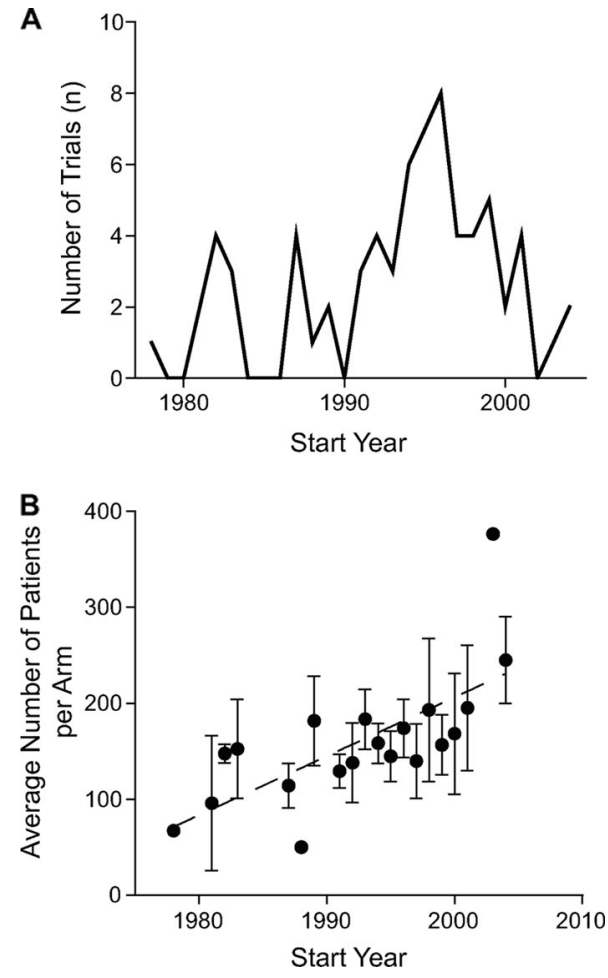

Figure 4. Chronological analysis of advanced breast cancer trials by start year $(n=70)$. (A): Phase III trials initiated by year. (B): Plot of number of patients per arm in phase III trials.

endpoints were considerably more common $(38 \%, n=27$ and $32 \%, n=23$, respectively). Primary study endpoints were NR in $21 \%(n=15)$ of trials. Of the trials initiated prior to 1995 , the majority of studies selected either RR as the primary endpoint or had an NR designation. After 1995, the proportion of NR designated trials decreased (18\% versus $3 \%$ ), whereas the proportion of trials reporting time-to-event endpoints, either PFS or TTP, increased (6\% versus 32\%). Survival was infrequently reported as a primary endpoint either before or after 1995 (3\% or 4\%, respectively).

Patterns of endpoint reporting for both first-line and second-line + trials mirrored those of trials overall. Studies reporting PFS and RR as primary endpoints were most common, followed by NR designated studies, whereas trials reporting OS as the primary endpoint were among the least common (Fig. 5C).

When outcomes from all phase III trials $(n=73)$ were reviewed, only a small proportion of trials demonstrated an OS gain $(12 \%, n=9)$ (Fig. 6A). Of the trials reporting OS as a primary endpoint $(n=5)$, only one trial $(20 \%)$ reported a significant OS gain [27] (Fig. 6B). Of the 27 studies reporting PFS/TTP as the primary endpoint, approximately half of the trials (52\%) reported significantly longer PFS/TTP.

When outcomes were considered for first-line trials $(n=$ 48 ), regardless of primary endpoint selection, OS gains were 
A
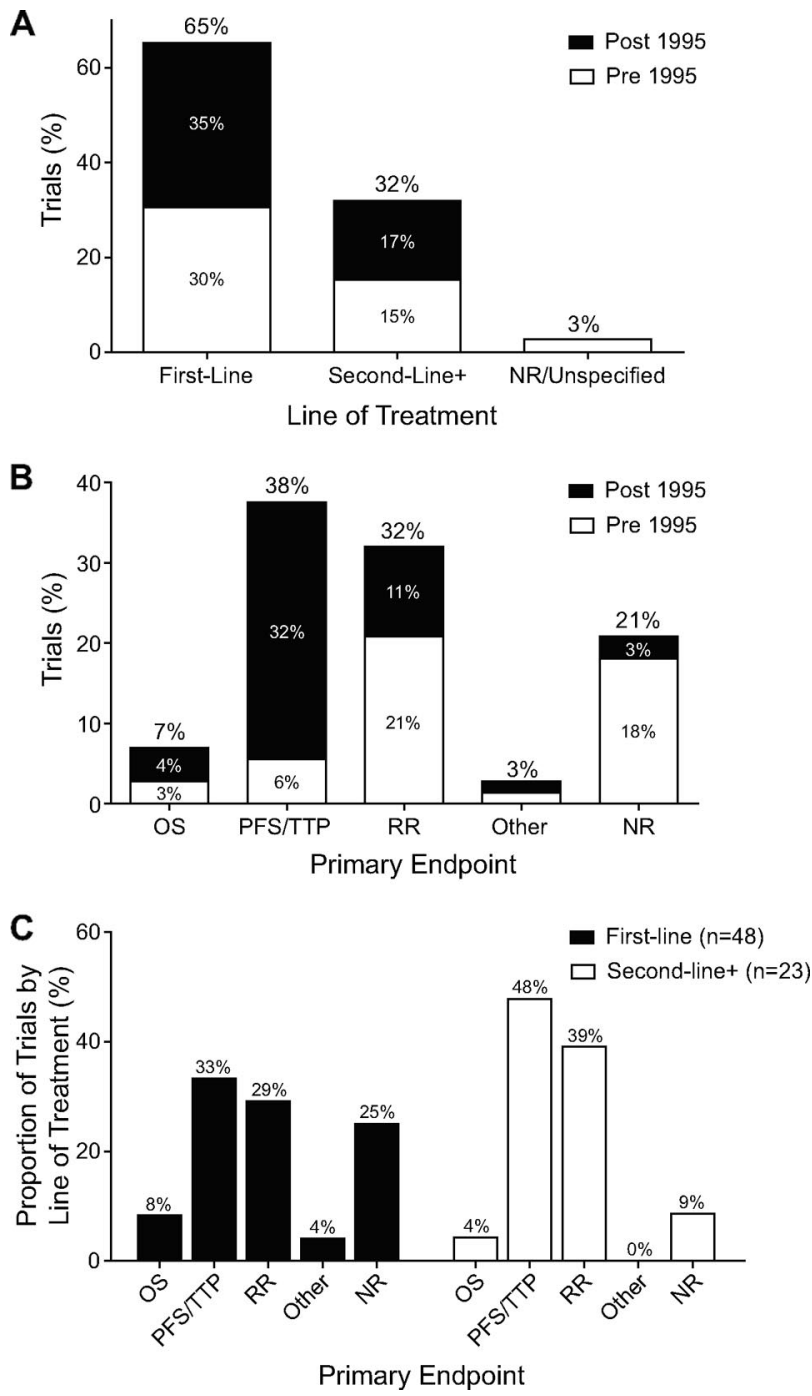

Figure 5. Trials started before and after $1995(n=72)$ categorized by line of treatment (A) or primary endpoint (B); (C): Frequency of primary endpoints in first-line trials or trials of second-line plus other lines of therapy (second-line + ).

Abbreviations: NR, not reported; OS, overall survival; PFS, progression-free survival; RR, response rate; TTP, time to progression.

observed in four trials (8\%), whereas PFS/TTP gains were observed in 14 trials (29\%) (Fig. 6C). Of the 23 second-line+ trials, five (22\%) reported longer OS times whereas 10 (43\%) reported longer PFS/TTP (Fig. 6D).

\section{FDA Regulatory ApProval}

\section{FDA Methods}

We reviewed the approval history of cytotoxic and biological NMEs for MBC approved by the FDA in 1996-2009. Data included: agent approved, year of approval, description of indication, type of approval (AA versus regular), trial design (phase III versus phase II), and endpoint used as
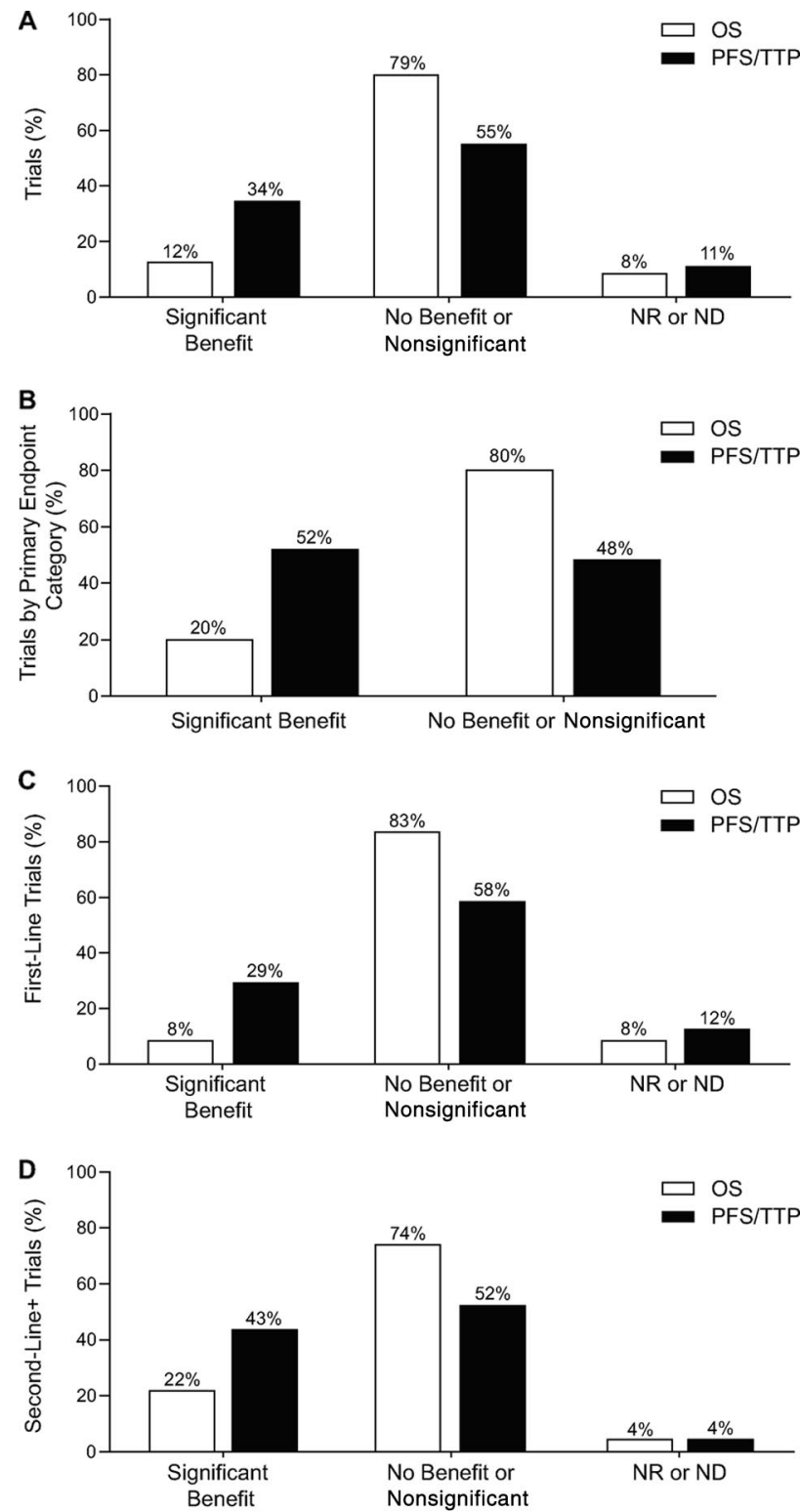

Figure 6. Frequency of significant improvements in OS and PFS/TTP of (A): All trials $(n=73)$; (B): Trials reporting OS $(n=5)$ or PFS/TTP $(n=27)$ as the primary endpoint; $(\mathbf{C})$ : First-line trials $(n=48)$; and (D): Trials of second-line plus other lines of therapy (second-line +$)(n=23)$.

Abbreviations: NR or ND, not reported or nondeterminable; OS, overall survival; PFS, progression-free survival; TTP, time to progression.

the basis for FDA approval. Data sources included documents publicly available on the FDA website (approval letters, medical and statistical reviews) [28], peer-reviewed or conference reports summarizing FDA findings [14-16, 29], transcripts from FDA advisory committee meetings [3, 22, 23], and package inserts. Cytotoxic and/or targeted systemic therapies approved by the FDA were classified as first-line or second-line + using the same definition as was used to classify clinical trials. 


\section{FDA Findings}

In 1996-2003, a period governed by early AA policy, two applications were granted AA for second-line+ disease and two applications were granted regular approval, one for second-line + and one for first-line disease (Table 2). In 1996 and 1998, respectively, docetaxel (Taxotere ${ }^{\circledR}$; sanofiaventis, Bridgewater, NJ) and capecitabine (Xeloda ${ }^{\circledR}$; Hoffmann-La Roche) were granted AA based on higher ORRs reported by phase II registration trials that enrolled patients who were resistant to specified treatments $[15,28]$. Regular approval was granted in 1998 and 2001, respectively, for the use of these agents in patients having failed prior therapy based on confirmatory phase III trials demonstrating survival benefits. In 1998, two trastuzumab (Herceptin $^{\circledR}$; Genentech, San Francisco, CA) applications were granted tandem regular approval for use in patients with human epidermal growth factor receptor (HER) $-2^{+}$disease. Trastuzumab in combination with paclitaxel (Taxol ${ }^{\circledR}$; Bristol-Myers Squibb, New York) was approved for first-line disease based on a phase III registration trial demonstrating an independently reviewed longer TTP and a statistically significant greater 12-month survival rate for patients receiving trastuzumab and chemotherapy [3]. Patients in the trastuzumab and paclitaxel subgroup had a longer TTP with a trend toward longer survival [28]. Single-agent trastuzumab was approved for use in patients with relapsed disease based on a phase II registration trial demonstrating a higher ORR and supported by the first-line breast cancer approval [3, 28].

In 2004-2009, a period governed by current AA policy, five applications were granted regular approval and one application was granted AA. Of the six approvals, four applications were for second-line + disease, and two were for first-line disease. Two applications for the use of ixabepilone (Ixempra ${ }^{\circledR}$; Bristol-Myers Squibb, New York) in resistant disease were granted tandem regular approval in 2007; the use of ixabepilone in combination with capecitabine in resistant disease was approved based on an independently confirmed longer PFS interval in a phase III registration trial [28], and the use of ixabepilone monotherapy in highly resistant patients was approved based on a greater ORR in a phase II registration trial and supported by the first-line approval [3]. Nab-paclitaxel (Abraxane ${ }^{\circledR}$; American Bioscience, Blauvelt, NY) and lapatinib (Tykerb ${ }^{\circledR}$; GlaxoSmithKline, Philadelphia) were also granted regular approval for the treatment of relapsed MBC patients; in 2005, nab-paclitaxel monotherapy was approved under regulation 505(b)(2) based on the results of a phase III, noninferiority trial demonstrating a higher target lesion response rate than with paclitaxel; lapatinib in combination with capecitabine was approved in 2007 for use in patients with
HER $-2^{+}$tumors based on the results of an independent review of a phase III registration trial demonstrating a longer TTP [28]. Finally, applications for gemcitabine (Gemzar ${ }^{\circledR}$; Eli Lilly, Indianapolis) and bevacizumab (Avastin ${ }^{\circledR}$; Genentech, San Francisco) were approved for use in first-line disease; in 2004, gemcitabine in combination with paclitaxel was granted regular approval based on interim phase III data demonstrating an independently confirmed longer TTP and a strong trend toward longer survival ( $p=.0489$ ), whereas bevacizumab in combination with paclitaxel was granted AA in 2008 for first-line use in patients with HER-2 ${ }^{-}$disease based on independently confirmed phase III data demonstrating a longer PFS interval in the absence of longer OS [28].

\section{DISCUSSION}

\section{MBC Studies and Sensitivity to Detect OS Gain}

Our review of outcomes from 73 phase III MBC trials, conducted over the last three decades, reveals considerable discordance between regulatory standards for outcomes in $\mathrm{MBC}$ and clinical trial design. Although demonstration of a longer OS time is considered the primary measure of clinical benefit in $\mathrm{MBC}$, especially for first-line trials, only five of 73 trials overall (7\%) and four of 48 first-line trials (8\%) reported OS as a primary endpoint. These findings indicate that only a very small number of trials had the capacity to detect improvements in survival. Not surprisingly, when trial outcomes were reviewed, a strikingly small proportion of trials overall $(12 \%, n=9)$ and even fewer first-line trials $(8 \%, n=4)$ demonstrated OS gains. These findings suggest that OS is not used by investigators as a primary endpoint and most trials are not powered to detect OS benefits.

Similar observations were recently published by Saad et al. [30] as well as by Wilcken and Dear [31]. Although there were differences in the prospective, systematic, trial selection criteria applied in our study, observations regarding OS outcomes were comparable. Saad et al. reviewed eligible trials $(n=76)$ that investigated systemic therapy, including predominantly cytotoxic, biological, and endocrine therapy, published in selected journals over the last decade (1998-2007) and found that $19.7 \%$ of trials demonstrated OS gains. Wilcken and Dear reviewed 63 studies obtained from the Cochrane Breast Cancer Group database and American Society of Oncology abstracts for 2000-2007 and reported that $13 \%$ of trials demonstrated significant OS gains. Although differences in trial selection may explain differences in the proportions of trials reporting OS effects ( $12 \%$ versus $19.7 \%$ versus $13 \%$ ), the findings overall support a lack of an OS effect in individual MBC trials.

Although some have begun to question the rigor of clin- 
Table 2. Regulatory approval of agents in advanced breast cancer [3, 28]

\begin{tabular}{|c|c|c|c|c|c|}
\hline Drug & Year & $\begin{array}{l}\text { Line of } \\
\text { therapy }\end{array}$ & Approved indication & $\begin{array}{l}\text { Approval } \\
\text { type }\end{array}$ & $\begin{array}{l}\text { Trial design } \\
\text { (supporting } \\
\text { endpoint) }\end{array}$ \\
\hline \multicolumn{6}{|c|}{ First period (1996-2003) } \\
\hline \multirow[t]{2}{*}{$\begin{array}{l}\text { Docetaxel } \\
\text { (Taxotere }^{\circledR} \text { ) }\end{array}$} & 1996 & Second-line + & $\begin{array}{l}\text { Taxotere }{ }^{\circledR} \text { (docetaxel) for injection concentrate is indicated } \\
\text { for the treatment of patients with locally advanced or } \\
\text { metastatic breast cancer who have progressed during } \\
\text { anthracycline-based therapy or have relapsed during } \\
\text { anthracycline-based adjuvant therapy }\end{array}$ & Accelerated & Phase II (ORR) \\
\hline & 1998 & Second-line + & $\begin{array}{l}\text { Taxotere }{ }^{\circledR} \text { (docetaxel) for injection concentrate for the } \\
\text { treatment of patients with locally advanced or metastatic } \\
\text { breast cancer after failure of prior chemotherapy }\end{array}$ & Regular & Phase III (survival) \\
\hline \multirow[t]{2}{*}{$\begin{array}{l}\text { Capecitabine } \\
\left(\text { Xeloda }^{\circledR}\right)\end{array}$} & 1998 & Second-line + & $\begin{array}{l}\text { Xeloda }{ }^{\circledR} \text { (capecitabine) tablets for the second-line } \\
\text { treatment of patients with anthracycline- and paclitaxel- } \\
\text { resistant metastatic disease }\end{array}$ & Accelerated & Phase II (ORR) \\
\hline & 2001 & Second-line + & $\begin{array}{l}\text { Xeloda }{ }^{\circledR} \text { (capecitabine) tablets in combination with } \\
\text { Taxotere }{ }^{\circledR} \text { (docetaxel) for the treatment of patients with } \\
\text { locally advanced or metastatic breast cancer after failure of } \\
\text { prior anthracycline-containing chemotherapy }\end{array}$ & Regular & Phase III (survival) \\
\hline \multirow[t]{2}{*}{$\begin{array}{l}\text { Trastuzumab } \\
\left(\text { Herceptin }{ }^{\circledR}\right)\end{array}$} & 1998 & Second-line + & $\begin{array}{l}\text { Trastuzumab is indicated for treatment of patients with } \\
\text { metastatic breast cancer whose tumors overexpress the } \\
\text { HER-2 protein and who have received one or more } \\
\text { chemotherapy regimens for their metastatic disease }\end{array}$ & Regular & Phase II (ORR) \\
\hline & 1998 & First-line & $\begin{array}{l}\text { Trastuzumab in combination with paclitaxel is indicated } \\
\text { for treatment of patients with metastatic breast cancer } \\
\text { whose tumors overexpress HER-2 protein and who have } \\
\text { not received chemotherapy for their metastatic disease }\end{array}$ & Regular & $\begin{array}{l}\text { Phase III HCT versus } \\
\text { CT (TTP, by } \\
\text { independent review, } \\
\text { and } 1 \text {-year survival } \\
\text { rate) }\end{array}$ \\
\hline \multicolumn{6}{|c|}{ Second period (2004-2008) } \\
\hline \multirow[t]{2}{*}{$\begin{array}{l}\text { Ixabepilone } \\
\text { (Ixempra }{ }^{\circledR} \text { ) }\end{array}$} & 2007 & Second-line + & $\begin{array}{l}\text { Ixempra }{ }^{\circledR} \text { (ixabepilone) for injection in combination with } \\
\text { capecitabine for the treatment of patients with metastatic or } \\
\text { locally advanced breast cancer resistant to treatment with } \\
\text { an anthracycline and a taxane, or whose cancer is taxane } \\
\text { resistant and for whom further anthracycline therapy is } \\
\text { contraindicated }\end{array}$ & Regular & $\begin{array}{l}\text { Phase III (PFS, by } \\
\text { independent review) }\end{array}$ \\
\hline & 2007 & Second-line + & $\begin{array}{l}\text { Ixempra }{ }^{\circledR} \text { (ixabepilone) for injection as monotherapy for } \\
\text { the treatment of metastatic or locally advanced breast } \\
\text { cancer in patients whose tumors are resistant or refractory } \\
\text { to anthracyclines, taxanes, and capecitabine }\end{array}$ & Regular & $\begin{array}{l}\text { Phase II (ORR, by } \\
\text { independent review) }\end{array}$ \\
\hline $\begin{array}{l}\text { Nab-paclitaxel } \\
\left(\text { Abraxane }^{\circledR}\right)\end{array}$ & 2005 & Second-line + & $\begin{array}{l}\text { Abraxane }{ }^{\circledR} \text { for injectable suspension (paclitaxel protein- } \\
\text { bound particles for injectable suspension) for the treatment } \\
\text { of breast cancer after failure of combination chemotherapy } \\
\text { for metastatic disease or relapse within } 6 \text { months of } \\
\text { adjuvant chemotherapy; prior therapy should have included } \\
\text { an anthracyline unless clinically contraindicated }\end{array}$ & Regular & $\begin{array}{l}\text { Phase III } \\
\text { noninferiority } \\
\text { (TLRR) }\end{array}$ \\
\hline $\begin{array}{l}\text { Lapatinib } \\
\left(\text { Tykerb }^{\circledR}\right)\end{array}$ & 2007 & Second-line + & $\begin{array}{l}\text { Tykerb }^{\circledR} \text { in combination with capecitabine for the } \\
\text { treatment of patients with advanced or metastatic breast } \\
\text { cancer whose tumors overexpress HER-2 (ErbB-2) and } \\
\text { who have received prior therapy including an } \\
\text { anthracycline, a taxane, and trastuzumab }\end{array}$ & Regular & $\begin{array}{l}\text { Phase III (TTP, by } \\
\text { blinded independent } \\
\text { review) }\end{array}$ \\
\hline $\begin{array}{l}\text { Gemcitabine } \\
\left(\text { Gemzar }^{\circledR}\right)\end{array}$ & 2004 & First-line & $\begin{array}{l}\left.\mathrm{Gemzar}^{\circledR} \text { (gemcitabine } \mathrm{HCl}\right) \text { for injection in combination } \\
\text { with paclitaxel for the first-line treatment of patients with } \\
\text { metastatic breast cancer after failure of prior anthracycline- } \\
\text { containing adjuvant chemotherapy, unless anthracyclines } \\
\text { were clinically contraindicated }\end{array}$ & Regular & $\begin{array}{l}\text { Phase III (TTP, by } \\
\text { independent review, } \\
\text { and survival) }\end{array}$ \\
\hline $\begin{array}{l}\text { Bevacizumab } \\
\left(\text { Avastin }{ }^{\circledR}\right)\end{array}$ & 2008 & First-line & $\begin{array}{l}\text { Bevacizumab for use in combination with paclitaxel for the } \\
\text { treatment of patients who have not received chemotherapy } \\
\text { for metastatic HER }-2^{-} \text {breast cancer }\end{array}$ & Accelerated & $\begin{array}{l}\text { Phase III (PFS, by } \\
\text { independent review, } \\
\text { and no survival) }\end{array}$ \\
\hline \multicolumn{6}{|c|}{$\begin{array}{l}\text { anthracycline resistance is defined as progression while on therapy or within } 6 \text { months in the adjuvant setting or } 3 \text { months } \\
\text { in the metastatic setting. Taxane resistance is defined as progression while on therapy or within } 12 \text { months in the adjuvant } \\
\text { setting or } 4 \text { months in the metastatic setting. } \\
\text { Abbreviations: CT, chemotherapy; HCT, Herceptin plus chemotherapy; HER-2, human epidermal growth factor receptor } 2 \text {; } \\
\text { ORR, overall response rate; PFS, progression-free survival; Second-line+, mixed populations of first-line patients and } \\
\text { patients receiving prior therapy for metastatic breast cancer; TLRR, target lesion response rate; TTP, time to progression. }\end{array}$} \\
\hline
\end{tabular}

ical trial design, others have begun to question the feasibility of detecting OS effects in an era of multiple lines of
MBC therapy. Recent modeling by Broglio and Berry [32] has focused attention on the relationship between OS and 
postprogression survival (PPS). The model assumes that the investigational drug has a PFS benefit but no effect on PPS, and that the treatment-related improvement in PFS is carried over to a treatment-related improvement in OS. According to this model, the probability of detecting a statistically significant difference in OS is dependent on the length of the median PPS interval and the magnitude of difference in the PFS interval. Therefore, OS was found to be an appropriate primary endpoint when the median PPS interval was short; however, it was not considered to be an optimal endpoint when the PPS interval was $>12$ months, because of the greater likelihood that the effect would be diluted by subsequent lines of therapy. A recent study by Saad and colleagues [30] explored the relationship between OS and PPS in MBC patients and found that the average median PPS interval for cytotoxic or targeted MBC trials published in the last decade was 11.4 months overall-12.9 months for first-line trials and 8.5 months for second-line trials. These findings suggest that, in contrast to regulatory policy, OS may be a more appropriate endpoint for secondline trials, in which the PPS interval is shorter ( 8.5 months, second-line disease), whereas PFS and TTP may be more appropriate endpoints in first-line disease, in which the PPS interval is longer (12.9 months). Consistent with these findings, when we analyzed the occurrence of significant OS improvements in first-line disease regardless of primary endpoint $(n=48)$, only four studies reported gains in OS (8\%), whereas 14 trials (29\%) reported gains in PFS/TTP. In second-line + disease $(n=23)$, five trials in total reported OS gains (22\%), whereas 10 trials $(43 \%)$ reported gains in PFS/TTP.

Furthermore, there is evidence to suggest that survival may be improving for MBC patients overall [33-35]. Recent data from a population-based analysis of survival trends in 2,150 MBC patients treated at the British Columbia Cancer Agency in Canada published by Chia and colleagues confirmed previously reported survival trends in MBC and linked these to the use of new agents. A significantly longer survival time was observed for patients diagnosed in 1991-1995 than for those diagnosed in 1997-1998 $(p=.002)$, as well as for patients diagnosed in 1999 and 2001 versus those diagnosed in 1997-1998 ( $p=.05$ ) [36]. The study found that the longer survival times corresponded to greater use of systemic therapy for MBC; $75 \%$ of patients diagnosed in 1991-1992 were administered therapy whereas $>90 \%$ of patients diagnosed in 19942001 received therapy. Moreover, improvements in survival appeared to be associated with differences in the use of agents or combinations over time. For instance, the largest median OS gain ( $\sim 4$ months; $p=.002$ ) was observed in patients diagnosed in 1997-1998, the period corresponding to the introduction of aromatase inhibitors, docetaxel, and trastuzumab, all agents that demonstrated longer survival times in individual trials. The findings may be explained, in part, by changes in the use of diagnostic or imaging technology and the safety of newer agents; however, they also support the notion that widespread access to newer therapies that have demonstrated superior outcomes, either gains in OS or PFS/TTP, can translate into greater populationbased survival benefits in MBC patients.

\section{Use of Non-OS Endpoints in Regulatory Approval}

FDA regulatory policy holds that an improvement in OS or an established surrogate of OS is the gold standard for full approval of NMEs in MBC, although in recent years the introduction of AA policy has allowed for NME approval based non-OS endpoints that are likely to predict OS [3]. Our review of the regulatory history revealed that, of the 37 phase III trials conducted in the last 15 years, only 12 new systemic therapies were approved for the treatment of MBC since 1995. Of these, eight systemic therapies in total were approved based on non-OS outcomes (Table 2). Of the 26 phase III trials conducted in first-line disease, only three new systemic therapies were approved for first-line treatment-two based on OS-outcomes and one based on non-OS outcomes [28].

The debate regarding appropriate measures of clinical benefit in MBC patients is ongoing [3]. Proponents of non-OS measures of clinical benefit argue that, in an era of multiple lines of subsequent therapy, PFS and TTP should be considered true endpoints because they are not affected by subsequent lines of therapy, and that slowing disease progression has intrinsic clinical and psychological value from the patient's perspective. However, the recent ODAC recommendation [37] to withdraw the breast cancer indication from the bevacizumab label despite a modest and statistically significant PFS effect has raised questions regarding the magnitude of effect that should be considered clinically significant as well as whether assessment of PFS should be based on median values or hazard ratios. The lack of reproducibility of the PFS benefit seen in initial studies underscores the importance of rigorous, blinded clinical trial design and independent review of treatment outcomes when considering non-OS outcomes.

The question of which endpoints are of intrinsic value was recently addressed in a survey conducted by SheikYousouf and colleagues at the University of Toronto, Toronto, Canada [10]. In total, 28 Canadian breast cancer oncologists responded to the survey. When asked to state the most important endpoint in selecting a therapy for their MBC patients, $54 \%$ of clinicians reported that OS was most 
important whereas $46 \%$ felt that PFS and TTP were important. When asked what magnitude of effect would make treatment worthwhile, clinicians indicated that an absolute gain in OS of 2-6 months would be warranted to justify treatment. These results are limited by a small sample size; however, the findings indicate that clinicians were divided between PFS/TTP and OS as the most important endpoint, underscoring the intrinsic clinical value of PFS/TTP.

The question of measuring clinical benefit becomes even more complex in light of our evolving understanding of the molecular heterogeneity of breast cancer. The ability to group tumors based on molecular signatures indicates varied tumor biology and the potential for divergent responses to a specific therapy. Important examples are studies that appear to be negative with regard to OS in unselected populations, but with biological understanding, subgroups are subsequently identified that have significant benefits; for example, cetuximab (Erbitux ${ }^{\circledR}$; ImClone and Bristol-Myers Squibb) [38-40] and panitumumab (Vectibix ${ }^{\circledR}$; Amgen, Thousand Oaks, CA) [41] in wild-type (nonmutated) $K$-ras colorectal cancers. Given the emergence of molecular pathology and personalized medicine, there is an even greater urgency for collaboration between researchers and regulators.

\section{CONCLUSIONS}

Taken together, our findings have identified multiple important causes and implications of the current lack of efficiency in drug development for MBC. We have identified substantial discordance between the conduct and design of clinical trials and historical measures of clinical benefit. Although regulatory approvals continue to hold OS as the gold standard, few phase III trials have the capacity to detect OS effects, especially in the first-line setting. These findings underscore the importance of a unity of vision and better collaboration between clinical researchers and regulators worldwide in planning and implementing clinical trials in the MBC setting.

There is increasing evidence to suggest that populationbased survival is improving for MBC patients overall, which supports the notion that widespread access to newer therapies can prolong OS, even though only a few regimens have been associated with longer OS times in individual trials. These findings should be validated and, if confirmed, factored into the debate on how standards of clinical benefit in $\mathrm{MBC}$ are determined.

\section{In the End, What Matters Most?}

In the end, what matters most is that safe and effective treatments that benefit patients be made available in a timely fashion. To this end, we urge patients, clinicians, researchers, and regulators to reach a consensus on how best to measure clinical benefit in MBC therapy, and to work together to ensure that this standard forms the foundation of study design, conduct, analysis, drug approval, and drug reimbursement for new MBC agents.

\section{ACKNOWLEDGMENTS}

Kaleidoscope Strategic, an independent medical information management firm, was engaged by the lead author of this review to assist in review development and reported directly to the lead author. The firm assisted in data collection and analysis, administrative support as well as writing. Their services were funded through an unrestricted educational grant from Hoffmann-La Roche, Canada. The sponsor did not contribute to the design or development of the article and has not seen the final manuscript. The opinions presented in the paper represent those of the authors and not the sponsor.

\section{Author Contributions}

Conception/Design: Sunil Verma, André Robidoux, John R. Mackey

Administrative support: Sunil Verma, Deanna McLeod, André Robidoux, John R. Mackey

Collection and/or assembly of data: Sunil Verma, Deanna McLeod, André Robidoux, Ilídio R. S. Martins, John R. Mackey

Data analysis and interpretation: Sunil Verma, Deanna McLeod, André Robidoux, Ilídio R. S. Martins, John R. Mackey

Manuscript writing: Sunil Verma, Deanna McLeod, Gerald Batist, André Robidoux, Ilídio R. S. Martins, John R. Mackey

Final approval of manuscript: Sunil Verma, Deanna McLeod, Gerald Batist, André Robidoux, Ilídio R. S. Martins, John R. Mackey

The authors take full responsibility for the content of the paper but thank Robert McLeod (Kaleidoscope Strategic, supported by Hoffmann-La Roche, Canada) for his assistance in conducting the literature search as well collecting and collating data.

\section{REFERENCES}

1 U.S. Department of Health and Human Services, U.S. Food and Drug Administration. Guidance for Industry: Clinical Trial Endpoints for the Approval of Cancer Drugs and Biologics. Available at http://www.fda.gov/ downloads/Drugs/GuidanceComplianceRegulatoryInformation/Guidances/ ucm071590.pdf, accessed April 20, 2010.

2 Pazdur R. Endpoints for assessing drug activity in clinical trials. The Oncologist 2008;13(suppl 2):19-21.

3 Oncologic Drugs Advisory Committee. Transcript From Meeting on December 5, 2007. CDER Meeting Documents 2007. Available at http://
www.fda.gov/OHRMS/DOCKETS/AC/cder07.htm\#OncologicDrugs, accessed April 20, 2010.

4 Hackshaw A, Knight A, Barrett-Lee P et al. Surrogate markers and survival in women receiving first-line combination anthracycline chemotherapy for advanced breast cancer. Br J Cancer 2005;93:1215-1221.

5 Miksad RA, Zietemann V, Gothe R et al. Progression-free survival as a surrogate endpoint in advanced breast cancer. Int $\mathrm{J}$ Technol Assess Health Care 2008;24:371-383.

6 Sherrill B, Amonkar M, Wu Y et al. Relationship between effects on timeto-disease progression and overall survival in studies of metastatic breast cancer. Br J Cancer 2008;99:1572-1578. 
7 Burzykowski T, Buyse M, Piccart-Gebhart MJ et al. Evaluation of tumor response, disease control, progression-free survival, and time to progression as potential surrogate end points in metastatic breast cancer. J Clin Oncol 2008;26:1987-1992.

8 Saad ED, Katz A. Progression-free survival and time to progression as primary end points in advanced breast cancer: Often used, sometimes loosely defined. Ann Oncol 2009;20:460-464.

9 Saad ED, Katz A, Hoff PM et al. Progression-free survival as surrogate and as true end point: Insights from the breast and colorectal cancer literature. Ann Oncol 2010;21:7-12.

10 Sheik-Yousouf A, Gandhi S, Dukhovny S et al. A comparison of physician and patient perceptions of clinically important endpoints in the treatment of metastatic breast cancer (MBC). Eur J Cancer Suppl 2010;8:1.

11 Sledge GW. The measure of our success. Clin Breast Cancer 2007;7:1.

12 Chakravarty A, Sridhara R. Use of progression-free survival as a surrogate marker in oncology trials: Some regulatory issues. Stat Methods Med Res 2008; 17:515-518.

13 Freidlin B, Korn EL, Hunsberger S et al. Proposal for the use of progression-free survival in unblinded randomized trials. J Clin Oncol 2007;25: 2122-2126.

14 Johnson JR, Williams G, Pazdur R. End points and United States Food and Drug Administration approval of oncology drugs. J Clin Oncol 2003;21: 1404-1411.

15 Dagher R, Johnson J, Williams G et al. Accelerated approval of oncology products: A decade of experience. J Natl Cancer Inst 2004;96:1500-1509.

16 Sridhara R, Johnson JR, Justice R et al. Review of oncology and hematology drug product approvals at the US Food and Drug Administration between July 2005 and December 2007. J Natl Cancer Inst 2010;102:230243 .

17 U.S. Food and Drug Administration: Department of Health and Human Services. 21 Code of Federal Regulations, Part 314.200. 2009 (last revision).

18 Richey EA, Lyons EA, Nebeker JR et al. Accelerated approval of cancer drugs: Improved access to therapeutic breakthroughs or early release of unsafe and ineffective drugs? J Clin Oncol 2009;27:4398-4405.

19 Clinton B, Gore A. Reinventing the Regulation of Cancer Drugs, National Performance Review 1996. Available at http://www.fda.gov/ohrms/dockets/ ac/05/briefing/2005-4191B1_01_03-Reinvent-Cancer-Drugs.pdf, accessed April 20, 2010.

20 U.S. Senate and House of Representatives. Food and Drug Administration Modernization Act of 1997. Available at http://www.fda.gov/downloads/ RegulatoryInformation/Legislation/FederalFoodDrugandCosmeticAct FDCAct/SignificantAmendmentstotheFDCAct/FDAMA/FullTextof FDAMAlaw/UCM089145.pdf, accessed April 20, 2010.

21 Roberts TG Jr, Chabner BA. Beyond fast track for drug approvals. N Engl J Med 2004;351:501-505.

22 Oncologic Drugs Advisory Committee. Transcript From Meeting on June 7, 1999. CDER Meeting Documents 1999. Available at http://www.fda. gov/ohrms/dockets/ac/cder99t.htm\#Oncologic\%20Drugs\%20Advisory\% 20Committee, accessed April 20, 2010.

23 Oncologic Drugs Advisory Committee. Transcript From Meeting on November 8, 2005. CDER Meeting Documents 2005. Available at http:// www.fda.gov/ohrms/dockets/ac/cder05.html\#OncologicDrugs, accessed April 20, 2010.

24 Takeda A, Loveman E, Harris P et al. Time to full publication of studies of anti-cancer medicines for breast cancer and the potential for publication bias: A short systematic review. Health Technol Assess 2008;12:iii, ix-x, $1-46$.

25 Creagan ET, Green SJ, Ahmann DL et al. A phase III clinical trial comparing the combination cyclophosphamide, adriamycin, cisplatin with cyclophosphamide, 5-fluorouracil, prednisone in patients with advanced breast cancer. J Clin Oncol 1984;2:1260-1265.

26 Pannuti F, Iafelice G, Martoni A et al. A new six-drug antiblastic regimen (R 14) at low doses (micropolychemotherapy) compared to CMF in the treatment of metastatic breast cancer: Phase III study. Chemioterapia 1984; 3:216-219.

27 Albain KS, Nag SM, Calderillo-Ruiz G et al. Gemcitabine plus paclitaxel versus paclitaxel monotherapy in patients with metastatic breast cancer and prior anthracycline treatment. J Clin Oncol 2008;26:3950-3957.

28 U.S. Food and Drug Administration: Center for Drug Evaluation and Research. Drugs@FDA: FDA Approved Drug Products. October 27, 2009. Available at http://www.accessdata.fda.gov/scripts/cder/drugsatfda/, accessed October 27, 2009.

29 Cortazar P, Johnson JR, Justice R et al. Metastatic breast cancer (MBC): FDA approval overview. J Clin Oncol 2008;26(15 suppl):1013.

30 Saad ED, Katz A, Buyse M. Overall survival and post-progression survival in advanced breast cancer: A review of recent randomized clinical trials. J Clin Oncol 2010;28:1958-1962.

31 Wilcken N, Dear R. Chemotherapy in metastatic breast cancer: A summary of all randomised trials reported 2000-2007. Eur J Cancer 2008;44:22182225 .

32 Broglio KR, Berry DA. Detecting an overall survival benefit that is derived from progression-free survival. J Natl Cancer Inst 2009;101:1642-1649.

33 Greenberg PA, Hortobagyi GN, Smith TL et al. Long-term follow-up of patients with complete remission following combination chemotherapy for metastatic breast cancer. J Clin Oncol 1996;14:2197-2205.

34 Arveux P, Grosclaude P, Reyrat E et al. Breast cancer survival in France: A relative survival analysis based on 68,449 cases treated in the 20 French comprehensive cancer centers between 1980 and 1999. Proc Am Soc Clin Oncol 2003;22:Abstract 3437.

35 Giordano SH, Buzdar AU, Smith TL et al. Is breast cancer survival improving? Cancer 2004;100:44-52.

36 Chia SK, Speers CH, D'yachkova Y et al. The impact of new chemotherapeutic and hormone agents on survival in a population-based cohort of women with metastatic breast cancer. Cancer 2007;110:973-979.

37 Oncologic Drugs Advisory Committee. Transcript From Meeting on July 20, 2010. CDER Meeting Documents 2010. Available at http:// www.fda.gov/AdvisoryCommittees/CommitteesMeetingMaterials/Drugs/ OncologicDrugsAdvisoryCommittee/ucm195226.htm, accessed 19 August, 2010.

38 Bokemeyer C, Bondarenko I, Makhson A et al. Fluorouracil, leucovorin, and oxaliplatin with and without cetuximab in the first-line treatment of metastatic colorectal cancer. J Clin Oncol 2009;27:663-671.

39 Tol J, Koopman M, Cats A et al. Chemotherapy, bevacizumab, and cetuximab in metastatic colorectal cancer. N Engl J Med 2009;360:563-572.

40 Van Cutsem E, Köhne CH, Hitre E et al. Cetuximab and chemotherapy as initial treatment for metastatic colorectal cancer. N Engl J Med 2009;360: $1408-1417$.

41 Amado RG, Wolf M, Peeters M et al. Wild-type KRAS is required for panitumumab efficacy in patients with metastatic colorectal cancer. J Clin Oncol 2008;26:1626-1634. 